\title{
Metallurgy and processing of coloured gold intermetallics - Part l: Properties and surface processing
}

\author{
Ulrich E. Klotz
}

www.goldbulletin.org

\begin{abstract}
Blue and purple gold alloys form in the alloying systems of gold with gallium/indium and aluminium respectively and are known to be very brittle and to possess low corrosion resistance. Taking into account these drawbacks this paper describes the results of a European funded research project. The properties of the blue and purple gold alloys and coatings such as corrosion resistance, metal release rates, hardness and colour and the influence of alloying additions on these properties are presented and discussed. Surface engineering techniques and investment casting were used for manufacturing of jewellery items with selectively coated coloured surface. Coatings of $\mathrm{AuGa}_{2}$ and Auln $\mathrm{n}_{2}$ blue gold alloys were applied on 18kt gold and Sterling silver jewellery by electroplating, laser/torch cladding or dipping into liquid gallium. The suitability of blue gold coatings for jewellery purposes will be discussed in the light of reliability and feasibility. The work consists of two parts. Part I describes properties and surface processing techniques while Part II deals with investment casting and related alloy design of coloured gold alloys.
\end{abstract}

Research Institute Precious Metals \& Metals Chemistry (fem) Katharinenstrasse 17, D-73525 Schwaebisch Gmuend, Germany Tel: +49 7171 1006-46, Fax: +497171 1006-54,

E-mail: klotz@fem-online.de

\section{Introduction}

Special colours of gold such as purple, blue, brown or black have been attractive in jewellery applications for long time. In principle two ways exist to obtain coloured gold jewellery items, either by surface treatment of karat gold alloys (black, brown or blue gold) or by selection of special alloy compositions possessing the desired colour (purple and blue gold). Reviews about the colours of gold alloys and the different types of alloys were given by Cretu et al. [1], Corti [2] and Bhatia et al. [3]. Different patents on coloured gold alloys and surface treatment techniques for colouring of karat gold alloys exist $[4,5]$. Recently, the optical properties of thin purple gold layers were described by Supansomboon et al. [6].

In this work the results of a research project funded by the European Commission on the surface engineering of colour effects for gold alloys are described. In the following, the physical metallurgy of blue and purple gold alloys is discussed, their properties are assessed and methods for jewellery manufacturing are presented. The properties and microstructure of the jewellery items is critically assessed. Potential jewellery applications are described taking into account the properties of blue and purple gold alloys.

\section{Alloy metallurgy}

Purple and blue gold alloys form in the alloying systems of gold with aluminium, gallium and indium and are based on intermetallic phases with the stoichiometry $\operatorname{AuX}_{2}(X=A l, G a, I n)$ [7-9]. The compound $\mathrm{AuAl}_{2}$ is usually referred to as "purple gold" with nominally 19 karat. AuGa ${ }_{2}$ has a bluishhue and 14 karat while Auln ${ }_{2}$ has a deep blue colour and about 12 karat. The concentration ranges of the intermetallic compounds are very limited. Deviation 
from the stoichiometric composition results in a quick loss of colour. The crystal structure is of the $\mathrm{CaF}_{2}$ type, hence the intermetallic compounds are very brittle. All intermetallic compounds are congruent melting. Purple gold $\mathrm{AuAl}_{2}$ has a melting point of $1060^{\circ} \mathrm{C}$ with deep melting minima for higher and lower gold contents. The blue gold alloys $\mathrm{AuGa}_{2}$ and Auln $\mathrm{n}_{2}$ have a low melting point of $491^{\circ} \mathrm{C}$ and $541^{\circ} \mathrm{C}$, respectively. The melting minimum on the gold rich side is much less pronounced compared to the Au-Al system.

\section{Properties of blue and purple gold jewellery}

The critical properties of blue and purple gold are brittleness and low corrosion resistance and the influence of alloy composition on theses properties was investigated. Further investigations comprised colour, hardness and finishing properties of blue and purple gold.

Brittleness of blue and purple gold is an inherent property caused by the low number of slip systems in the intermetallic crystal structure $\left(\mathrm{CaF}_{2}\right.$ type). The brittleness of the alloys decreases from $\mathrm{AuAl}_{2}$ over $\mathrm{AuGa}_{2}$ to Auln ${ }_{2}$. A small grained two- or three-phase microstructure is required for the reduction of brittleness and mandatory for allowing use of these alloys for jewellery purposes $[4,10]$. Therefore, a composition slightly over stoichiometric in gold should be chosen, resulting in a two-phase microstructure of $\mathrm{AuX}_{2}$ (the coloured gold phase) and AuX (colourless phase) with $X=A l, G a$, In (Figure 1). The volume fraction of the second phase should be low in order to avoid bleaching of the colour. The solubility for third alloying element additions such as palladium, copper or silver in purple and blue gold

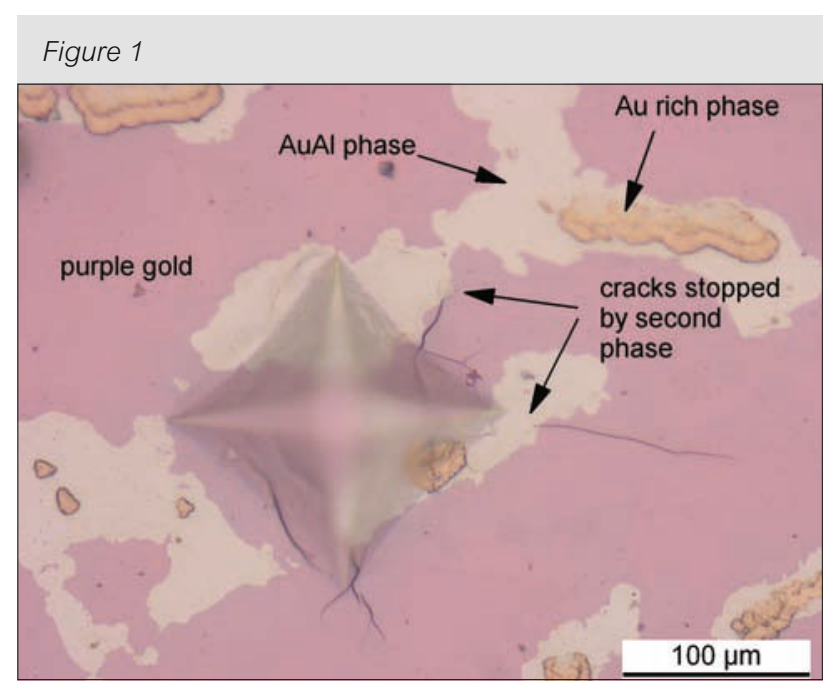

Three-phase microstructure of alloy Au76.2 Al19.8 Pd4 (weight \%). Crack deflection in the AuAl phase (white) around a hardness indent

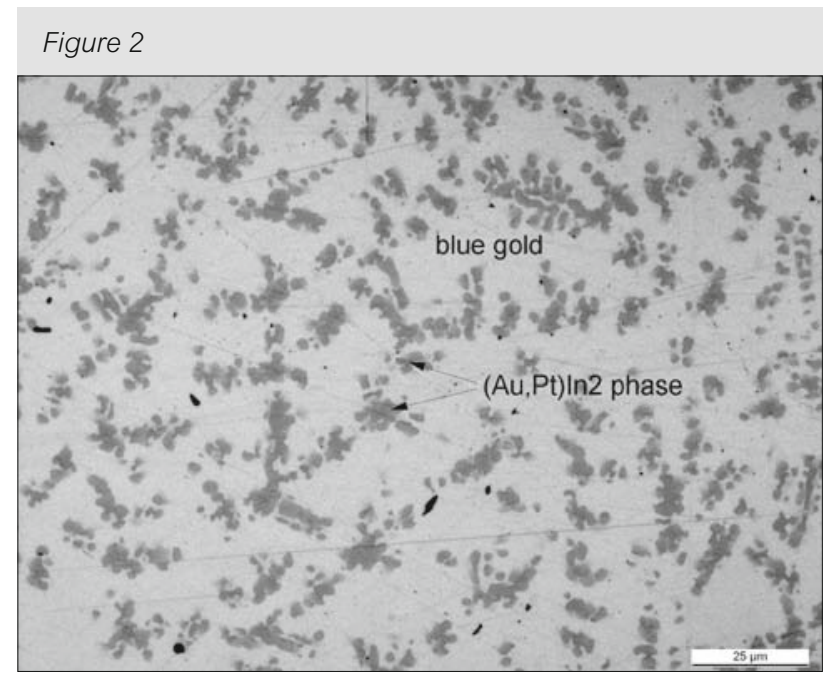

Microstructure of blue gold Auln ${ }_{2}$ with addition of 3 weight $\%$ PtIr10

\begin{tabular}{|c|c|c|c|c|c|}
\hline Composition [mass\%] & $\mathbf{L}$ & $\mathbf{a}$ & b & HV1 & Remarks \\
\hline Au99.9 & 86 & 4.7 & 36.9 & 28 & Fine gold \\
\hline Au58.5 Ga 41.5 & 81 & -1.0 & -2.1 & 75 & Blue gold $\mathrm{AuGa}_{2}$ \\
\hline Au46 In54 & 79 & -3.7 & -4.2 & 49 & Blue gold Auln \\
\hline Au36 In54 Pt10 & 81 & 0.2 & -1.3 & 134 & $(\mathrm{Au}, \mathrm{Pt}) \ln \mathrm{n}_{2}$ \\
\hline Au26 In54 Pt20 & 80 & 2.4 & 1.3 & - & $(\mathrm{Au}, \mathrm{Pt}) \mathrm{In}_{2}$ \\
\hline $\ln 54$ Pt46 & 78 & 5.1 & 12.1 & - & Ptln \\
\hline Au79 Al21 & 67 & 14.5 & -8.9 & 260 & Purple gold $\mathrm{AuAl}_{2}$ \\
\hline Au79.4 Al 18.6 Pd 2 & 71 & 9.1 & -1.9 & 308 & \\
\hline Au76.2 Al 19.8 Pd 4 & - & - & - & 334 & \\
\hline
\end{tabular}

Colour properties (CIE Lab coordinates) and hardness of blue and purple gold alloys in as-cast condition 
Table 2

\begin{tabular}{|c|c|c|c|c|c|c|}
\hline Alloy composition [mass \%] & Test method & $\mathrm{Au}$ & Al & $\mathbf{P d}$ & Ga & In \\
\hline Au78.5 Al21.5 & (DIN EN ISO 10271) & $<0.1$ & 580 & & - & - \\
\hline Au76.8 Al21.0 Pd2.1 & (DIN EN ISO 10271) & $<0.1$ & 550 & $<0.1$ & - & - \\
\hline Au76.2 Al19.8 Pd4.0 & (DIN EN ISO 10271) & $<0.1$ & 395 & $<0.1$ & - & - \\
\hline Au58.5 Ga41.5 & (DIN EN ISO 10271) & $<0.1$ & - & - & 2444 & - \\
\hline Au46.0 In54.0 & (DIN EN ISO 10271) & $<0.1$ & - & - & - & 798 \\
\hline Au58.5 Ga41.5 & (DIN 1811, 2 days) & $<0.1$ & - & - & 683 & - \\
\hline Au58.5 Ga41.5 & (DIN 1811, 7 days) & $<0.1$ & - & - & 2163 & - \\
\hline Au46.0 $\ln 54.0$ & (DIN 1811, 2 days) & $<0.1$ & - & - & - & 382 \\
\hline Au46.0 $\ln 54.0$ & (DIN 1811, 7 days) & $<0.1$ & - & - & - & 1226 \\
\hline
\end{tabular}

Metal release $\left[\mu \mathrm{g} / \mathrm{cm}^{2}\right]$ in lactic acid (DIN EN ISO 10271) and synthetic sweat (DIN 1811)

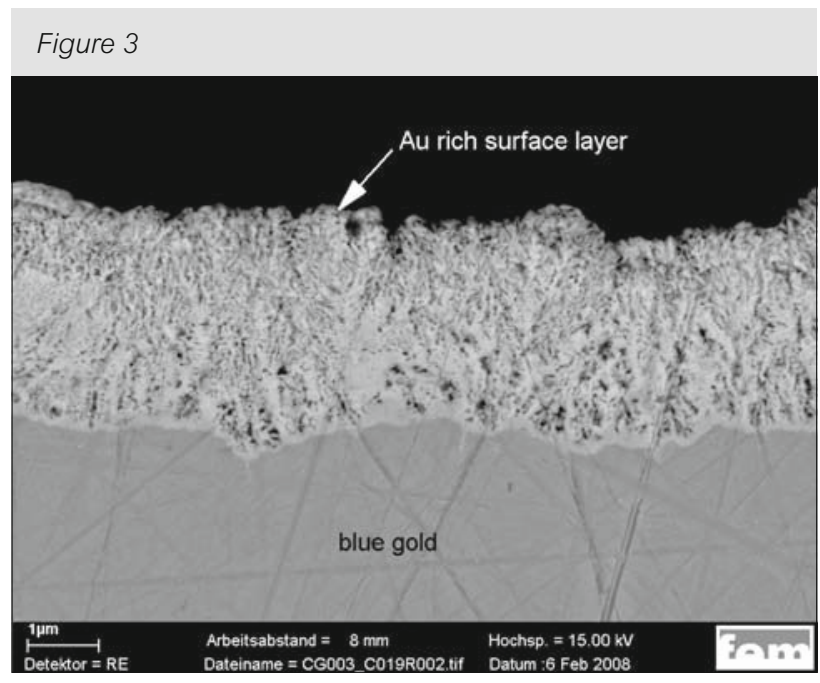

Gallium depletion on the surface during corrosion test

is very low. If more than 2 mass \% of one of these elements is added the colour of purple gold quickly fades. Interesting colour effects can be achieved by an exchange of gold with platinum while keeping a constant atom ratio of $(\mathrm{Au}, \mathrm{Pt}) \mathrm{X}_{2}$. Platinum forms the coloured intermetallic compound with the same stoichiometry $\mathrm{PtX}_{2}(\mathrm{X}=\mathrm{Al}, \mathrm{Ga}, \mathrm{In})$ and crystal structure [8]. The effect of platinum on the colour of blue gold Auln $n_{2}$ was demonstrated by colour measurements (Table 1). With increasing platinum content the colour changes from blue $\left(\right.$ Auln $\left.n_{2}\right)$ to apricot $\left(P t \mid n_{2}\right)$. For small additions of platinum the blue colour is slightly enhanced. Furthermore, the precipitation of the PtIn $n_{2}$ phase results in grain refinement of the blue gold matrix and therefore reduction of its brittleness. In case of Auln the addition of 3 mass \% Pt showed strong grain refinement, which was enhanced by additional 0.3 mass \% iridium (Figure 2). The hardness of blue and purple gold

\begin{tabular}{|ll|}
\hline Table 3 & \\
\hline Technique & Suitable for \\
\hline $\begin{array}{l}\text { Electroplating and } \\
\text { annealing } \\
\text { Surface cladding }\end{array}$ & Blue gold Auln ${ }_{2}$ \\
Liquid metal dip-coating & $\begin{array}{l}\text { Blue gold AuGa } \\
\text { and Auln }\end{array}$ \\
\hline
\end{tabular}

Processing techniques for coloured jewellery

alloys differs markedly. While blue gold and its alloys show relatively low hardness below 100HV1 purple gold and its alloys reach hardness values up 334HV1.

Metal release tests were performed for blue and purple gold alloys in artificial sweat (according to DIN 1811) and lactic acid (according to DIN EN ISO 10271). Both tests showed similar results (Table 2). Purple gold alloys showed very high release of aluminium and during the test the colour changed from purple to brownish. With increasing palladium content the aluminium dissolution decreased, but still remains at a high level. The effect of palladium is interpreted as a result of microstructural changes rather than an improvement of the corrosion resistance of purple gold. The blue gold alloys $\mathrm{AuGa}_{2}$ and Auln $n_{2}$ also showed a very high release of $\mathrm{Ga}$ and In, respectively. In case of $\mathrm{AuGa}_{2}$ the metal release was extremely high and within the first hours of the test the colour changed from blue to golden-brownish (Figure 3). The metallographic section revealed a Au-rich, spongy surface layer (2-3 $\mu \mathrm{m}$ thick), which was responsible for the colour change. Blue gold 


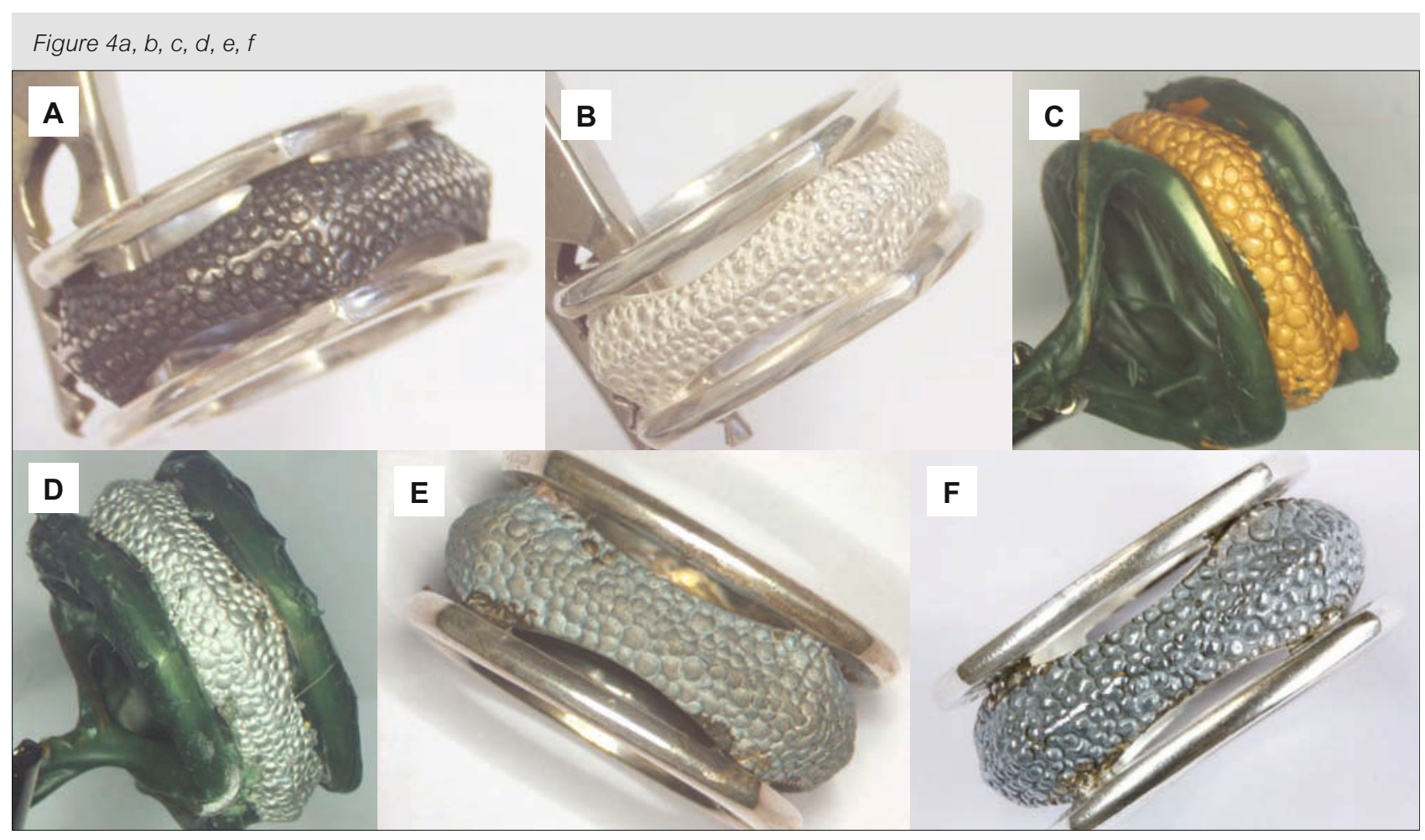

Preparation process for blue gold layers Auln, with a Sterling silver ring. a) Original Sterling silver ring, b) Cleaning, c) Masking and gold plating, d) In plating, e) after annealing, f) polished ring

Auln ${ }_{2}$ showed no colour or microstructure changes during the test, despite the high metal release. It was not possible to improve corrosion properties of blue and purple gold by alloying with third elements. As a consequence transparent, protective coatings are probably required for jewellery applications.

In terms of brittleness and corrosion resistance Auln $_{2}$ appears as most promising candidate for jewellery uses. However, brittleness and low corrosion resistance have to be taken into account in jewellery design.

Some recommendations for jewellery design are listed below:

- Filigree items and parts subjected to external mechanical forces should be avoided

- The jewellery piece should have a frame structure of a ductile alloy holding and protecting the coloured gold item.

- Coloured gold alloys are not suitable to set in stones, because of their brittleness.

- Direct contact with the skin should be avoided, because of corrosion by sweat.

- In a two-or multi-coloured jewellery piece coloured gold alloys might show enhanced corrosion in contact with conventional gold alloys.

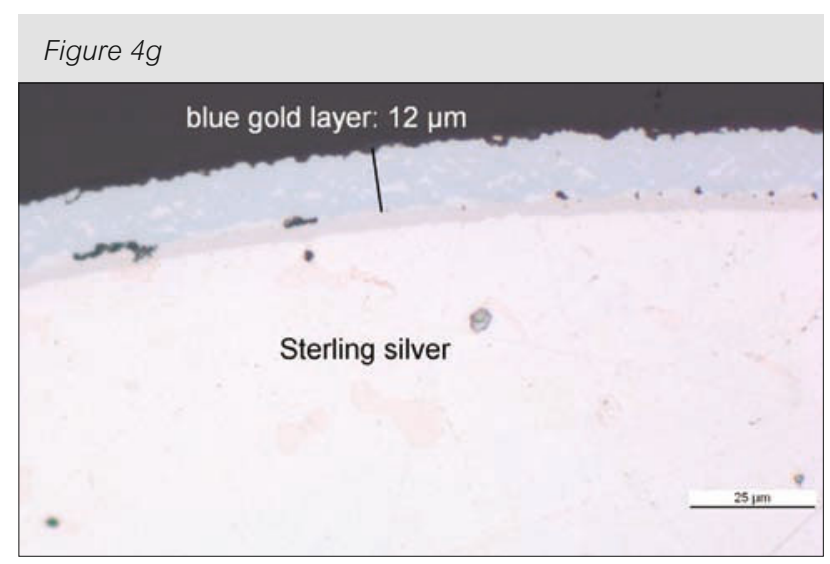

Preparation process for blue gold layers Aul $n_{2}$ with a Sterling silver ring. g) microstructure

- The protection of blue and purple gold by a transparent, wear resistant coating is probably essential.

\section{Processing techniques}

In this chapter different processing techniques for thick coatings of blue gold on karat gold or silver alloys are described. These techniques are based on diffusion surface alloying processes. Not all 


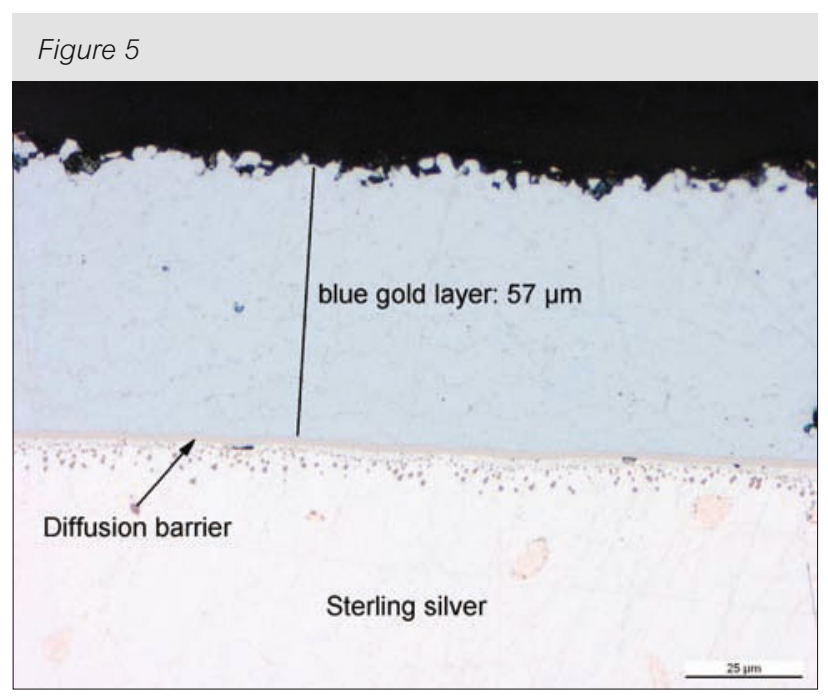

Homogeneous and defect-free Auln, layer on Sterling silver formed by electroplating and diffusion annealing

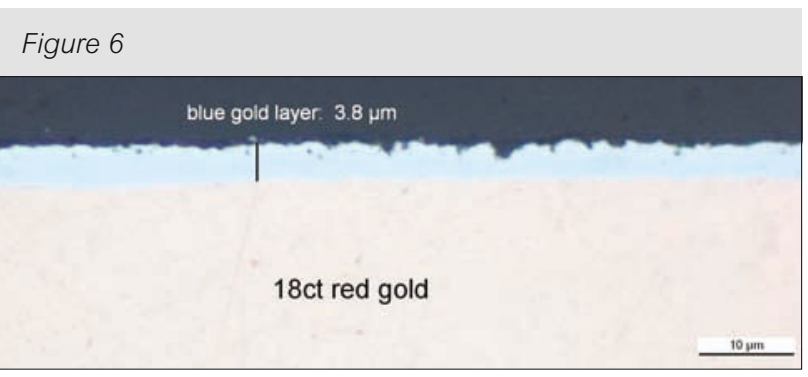

a) Wedding bands of 18 karat yellow, white and red gold with Auln, blue gold layer. b) Metallographic cross section for red gold

techniques can be applied for the different blue and purple gold alloys (Table 3). As alternative approach, adapted casting technologies are described in part II of this publication.

\section{Electroplating and annealing}

Electroplating was used to deposit layers of gold and indium on Sterling silver and karat gold alloys. During subsequent annealing a blue gold layer of Auln, was formed. For the gold layer a commercial electrolyte was used. For indium deposition an electrolyte based on Fink-Lester was used [11]. The thickness of the gold and indium layers were adjusted fulfilling the requested atomic percent ratio of $\mathrm{Au}: \ln =1: 2$. The different steps of the electroplating process are illustrated in Figure 4 for a Sterling silver ring. The gold layer was deposited first to avoid reaction between indium and silver during annealing. Annealing temperature and time to form the Auln layer was based on the reaction-diffusion velocity in the Au-In system $[12,13]$. During annealing the gold layer reacted completely with indium to form the Auln, layer. Thereby, Auln layers with thickness up to $50 \mu \mathrm{m}$ could be realized (annealing conditions $160^{\circ} \mathrm{C} / 140 \mathrm{~h}$, Figure 5). In order to avoid reaction with Sterling silver a diffusion barrier (rhodium or nickel) is required, especially in cases were thick blue gold layers are requested.

The electroplating and diffusion annealing technique was also used for karat gold jewellery. In case of gold substrates indium can be directly deposited on the jewellery item saving costs, efforts and time related to the gold deposition. This was demonstrated for 18 karat white, yellow and red gold wedding bands (Figure 6). A homogeneous and defect-free blue gold layer formed during annealing. The formation of other intermetallic compounds from the gold-indium system was not observed in that case.

\section{Surface cladding processes}

Surface cladding was tested with blue and purple gold rods and powder using a jewellery welding laser or a hydrogen torch. Substrate materials were 18 and 14 karat yellow and red gold and 950Pt alloy. The objective was filling machined grooves on rings with a thick blue gold cladding. The process was hand controlled under protective gas or air in case of using a laser or a hydrogen torch, respectively. The process is difficult to control manually, because of the melting minima observed in the binary systems. Defined, machine controlled process conditions will be necessary in order to achieve constant quality on a high level.

Purple gold can't be alloyed with gold based jewellery alloys by laser / torch welding or adapted casting technologies. Because of the deep melting minimum observed in Au-Al system alloying of purple gold with karat gold alloys results in the formation of low melting phases. However, casting experiments with palladium alloys were successful as described in part II.

Experiments with blue gold were partially successful. A working temperature of about $600^{\circ} \mathrm{C}$ is sufficient because of the low melting point of blue gold $\left(491^{\circ} \mathrm{C}\right.$ for $\mathrm{AuGa}_{2}$ and $541^{\circ} \mathrm{C}$ for Auln ${ }_{2}$, respectively). Examples for two jewellery pieces with laser welded blue gold inlays are presented below. On an 18 karat yellow gold ring (Figure 7) complete form filling of a circular groove could be realized. A pronounced colour contrast between yellow and blue gold was maintained. The metallographic cross-section shows a nearly defect-free blue gold inlay with width of 


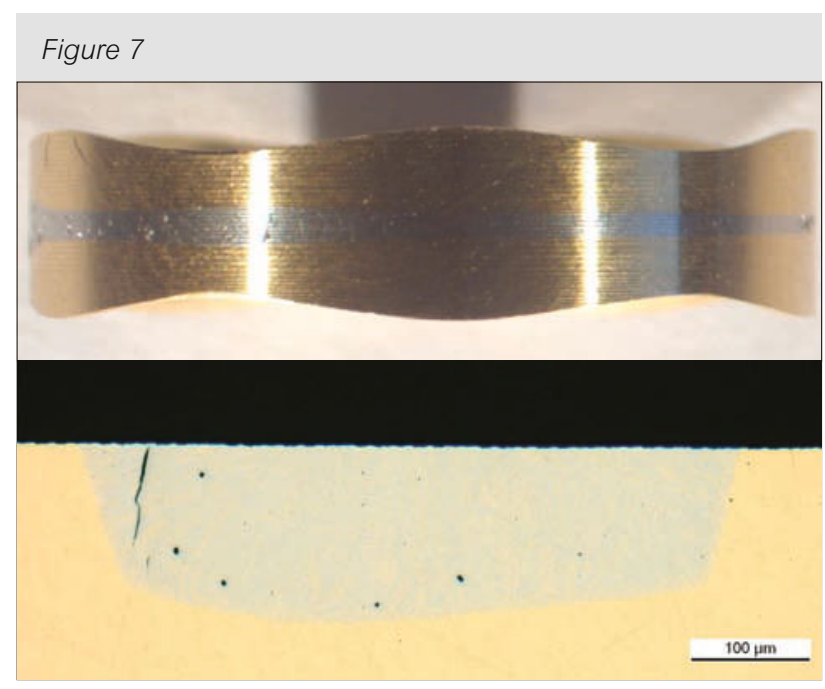

18 karat yellow gold ring with laser welded blue gold inlay and its microstructure

about $0.5 \mathrm{~mm}$ and a depth of about $140 \mu \mathrm{m}$. A twophase microstructure consisting of the blue gold phase and another more gold rich phase results after laser welding. Similar results were obtained for a 14 karat red gold ring with hydrogen torch welding.

\section{Liquid metal dip-coating}

Dipping of jewellery pieces into liquid gallium or indium appeared being a very simple and easy to use technique, especially under workshop conditions. Because of its low melting point of $29.8^{\circ} \mathrm{C}$ gallium can be melted easily on a hot plate. Dipping experiments were performed at $90^{\circ} \mathrm{C}$ with fine gold sheets. Once the gallium wetted the fine gold a film of liquid gallium on the gold surface formed, which transformed to $\mathrm{AuGa}_{2}$ at room temperature within a few days. In these experiments defect-free layers of $\mathrm{AuGa}_{2}$ with a thickness of 40-80 $\mu \mathrm{m}$ were obtained for 10-30min dipping time (Figure 8). Unfortunately, such experiments could not be repeated successfully for jewellery items, because of the poor wetting of gold by gallium. In order to avoid oxidation of gallium very clean surfaces and atmosphere would be required. This can only be realized under high vacuum conditions, which are no longer feasible under workshop conditions.

\section{Potential jewellery applications}

Conventional jewellery application of purple and blue gold is in form of cast and ground items, which are set similar to gemstones. Due to the inherent brittleness the setting has to provide enough strength keeping mechanical stress away from the blue or purple gold part.

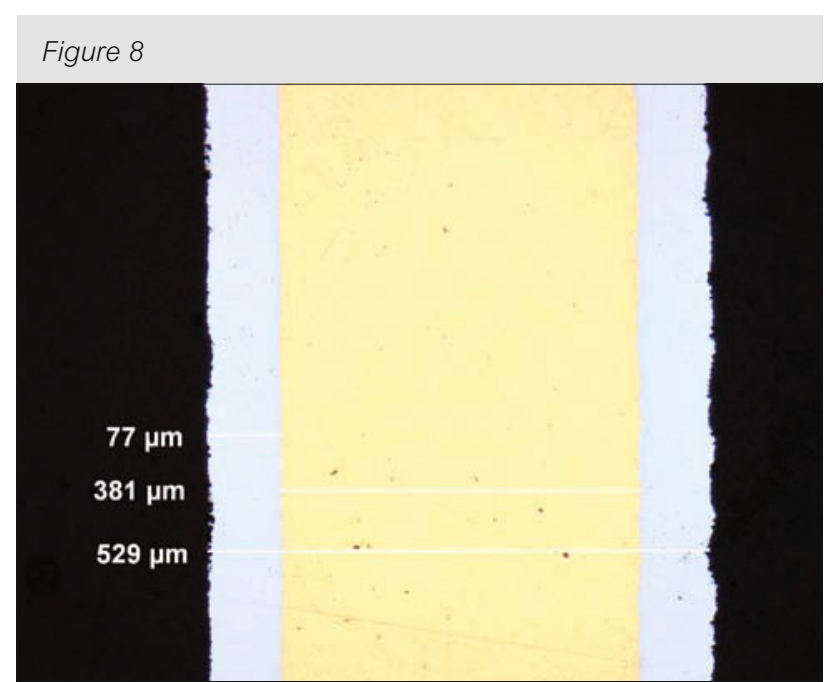

Blue gold layer of $\mathrm{AuGa}_{2}$ on fine gold after dip-coating

In order to manufacture partially coloured jewellery items a selective coating process might be better suited. By such coating the aspect of brittleness becomes much less critical. Based on the experience gathered during the research project electroplating / annealing and an adapted casting technique turned out to be the most reliable processes to obtain coloured layers on karat gold alloys, Sterling silver, palladium or platinum alloys. The electroplating/ annealing process works with blue gold Auln ${ }_{2}$ by direct electroplating of indium on karat gold alloys. On other materials gold and indium layers have to be deposited with certain thickness ratio. In some cases a diffusion barrier layer might be required.

Poor corrosion resistance is also an inherent property of blue and purple gold alloys, which can't be changed by alloying measures. In metal release tests with synthetic sweat or lactic acid high release rates for aluminium, gallium and indium were found. During the test the colour was lost and blue and purple gold became golden-brownish. This is caused by a gold rich layer, which can be polished off easily to obtain the blue / purple colour again. Blue gold Auln $\mathrm{n}_{2}$ had the lowest release rate, i.e. the highest corrosion resistance and did not show a colour change during the metal release test. As a consequence of the high metal release rates direct contact of blue and purple gold jewellery with skin should be avoided as the released metal might be absorbed by the human body. In bicoloured or multicoloured jewellery where blue / purple gold is in contact with karat gold or other jewellery alloys enhanced corrosion due to local cell formation might occur. A transparent and wear-resistant coating 
is probably mandatory to protect the blue / purple gold jewellery from corrosion and to maintain the colour. First experiments with coatings showed promising results and an improvement of corrosion properties.

\section{Acknowledgements}

Financial support of this work by the European Commission under contract no. COOP-CT-2006032497 and allocation of a gold stock for research at fem by the World Gold Council is kindly acknowledged. The project partners of the "Coloured Gold" project are acknowledged for their contribution during the project and their allowance to publish these results. Special thanks to the staff members at fem.

\section{About the author}

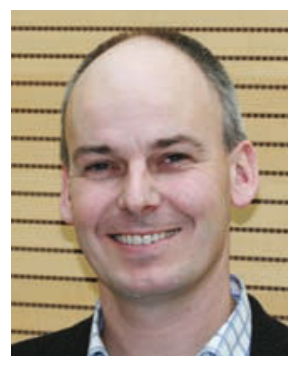

Dr. Ulrich E. Klotz is Diploma Engineer in Physical Metallurgy (University of Stuttgart, Germany) and has a PhD in Materials Science from ETH Zurich, Switzerland. He is Head of the Department of Physical Metallurgy at the Research Institute for Precious Metals \& Metals Chemistry (fem) in Schwaebisch Gmuend, Germany.

\section{References}

1 Cretu, C. and E. van der Lingen, Gold Bulletin, 1999, 32, 115-126

2 Corti, C.W. Blue, black and purple! The special colours of gold. in: The Santa Fe Symposium. ed. E. Bell. 2004. Albuquerque: Met-Chem Research. p. 121-133

3 Bhatia, V.K., et al., Gold Bulletin, 2009, 42, 201-208

4 EP 0284699 (1987) Steinemann, S.: Intermetallische Verbindung und ihre Verwendung

5 EP1175515 (A1) (2002) Chum, L.P.: Jewellery alloy compositions

6 Supansombon, S., A. Maaroof, and M.B. Cortie, Gold Bulletin, 2008, 41, 296-304

7 Wongpreedee, K., et al., Microstructure and Young's modulus study of Au-Al-In, in Gold 2009. 2009, World Gold Council: Heidelberg, Germany. p. 366

8 Massalski, T.B., Binary alloy phase diagrams. Vol. 1+2. 1986, Metals Park, Ohio: American Society of Metals

9 Masubuchi, K., et al., Blue coloured gold for ornaments, in Gold 2009. 2009: Heidelberg, Germany. p. 256

10 Wongpreedee, K., et al., Purple gold: past, present, and future to ductile intermetallics, in Gold 2006. 2006, World Gold Council: University of Limerick, Ireland. p. 163

11 Walsh, F.C. and D.R. Gabe, Surface Technology, 1979, 8 , 87-99

12 Millares, M., B. Pieraggi, and E. Lelievre, Solid State Ion., 1993, 63-65, 575-580

13 Millares, M., B. Pieraggi, and E. Lelièvre, Scripta Metallurgica et Materialia, 1992, 27, 1777-1782 